\title{
DAS SESMARIAS À RESISTÊNCIA AO CERCAMENTO: razões históricas dos Fundos de Pasto ${ }^{1}$
}

\author{
LuizAntonio FerraroJúnior" \\ MarcelBursztyn
}

\begin{abstract}
O artigo recupera as razões históricas para o surgimento da categoria dos fundos de pasto. Nele, são utilizados dados secundários recolhidos de relatórios governamentais e obtidos em entrevistas com técnicos, agentes pastorais e comunidades pastoris. Os fundos de pasto eram apenas áreas não-cercadas de Caatinga, utilizadas para pastoreio comunal. Esse padrão de ocupação, que se desenvolveu em todo o semiárido nordestino, foi progressivamente usurpado em um processo similar aos enclosures ingleses. Na Bahia, com os avanços do capital sobre essas áreas, a partir da década de 1970, houve articulações regionais e apoios institucionais que estimularam resistências diversas. Assim, "Fundo de Pasto" passou a designar não só as áreas, mas os grupos sociais que as defendiam por delas depender. O termo Fundo de Pasto, antes regional, generalizou-se por todo o estado, principalmente após sua citação na constituição baiana. Os vínculos familiares dessas comunidades também concorreram para a resistência dessa forma de ocupação.

PALAVRAS-CHAVE: fundos de pasto, enclosures, grilagem, terras comunais, caatinga.
\end{abstract}

Neste artigo, busca-se compreender os processos históricos que ensejaram o desenvolvimento, no sertão baiano, de um conjunto de aproximadamente 20.000 famílias, distribuídas por 500 comunidades, que vivem do pastoreio comunal. Trata-se da categoria dos Fundos de Pasto (FP). A história matricial dos FP refere-se ao longo período entre a criação das sesmarias, em 1534, e a generalização, na década de 1980, dessa alcunha como modo de designar essas comunidades pastoris do sertão baiano. Sendo o latifúndio o mainstream da formação do Brasil, formas como os FP se configuram em diálogo com seus fluxos e influxos. Esses povos vivem em conflito com o avanço dos latifúndios e em relativa autonomia quando eles arrefecem. Ainda assim, fazem parte do sistema latifundiário, a

${ }^{1}$ A pesquisa que subsidiou este artigo foi desenvolvida com o apoio de uma bolsa de doutorado do CNPq.

* Doutor em Desenvolvimento Sustentável. Professor adjunto da Universidade Estadual de Feira de Santana. Avenida Transnordestina, s/n Bairro Novo Horizonte. Cep: 44036-900. Feira de Santana - Bahia - Brasil. ferraroluiz@yahoo.com.br

* * Doutor em Desenvolvimento Econômico e Social e em Economia Pós-doutor em Políticas Públicas. Professor associado da Universidade de Brasília, junto ao Departamento de Sociologia e ao Centro de Desenvolvimento Sustentável. marcel@unb.br exemplo de outros grupos sociais que vivem nas suas "dobras" e "intervalos".

A tendência mundial ao desaparecimento de sistemas comunais, iniciada no século XIII com os enclosures ingleses, coincide com o avanço da mercantilização da terra e do trabalho (Polanyi, 2000). A cobiça de grileiros e latifúndios sobre áreas comunais da caatinga decorre da mercantilização da terra. Os sistemas comunitários remanescentes estão normalmente associados a situações de fraca inclusão no mercado e à conservação dos biomas dos quais dependem.

O sertão nordestino foi ocupado de modo rarefeito, subordinado economicamente à economia açucareira, inicialmente pujante e que decaiu durante os séculos XVIII e XIX. O esfacelamento das grandes sesmarias - como das Casas da Ponte e da Torre -, entre o final do século XVIII e início do século XIX, decorrente da queda da economia do açúcar, permitiu o estabelecimento e a formação de um campesinato advindo de famílias de vaqueiros, agregados e outros recém-chegados, num processo de acampesinamento relacionado ao apossamento comunal das terras. O descontro- 
le do Estado sobre essas terras, o desinteresse econômico por elas e seu relativo isolamento geográfico são aspectos que favoreceram seu desenvolvimento. No sertão, essas condições perduraram sem alterações bruscas e exógenas até as décadas de 1970 e 1980, quando o cercamento de grandes áreas criou choques com os usos costumeiros. A partir daí, atos mais ou menos isolados de resistência comunitária e o "reconhecimento" desses usos costumeiros por parte de uma fração do Estado criaram as condições que transformaram um padrão de ocupação e uso da terra em uma nova categoria social.

Existem poucos estudos históricos sobre os FP. Há diversas teorias sobre a sua origem. Ouvem-se várias versões: “sempre houve os FP”, “os FP é coisa nova”, "têm origem portuguesa”, "isso de criar solto é coisa que vem dos índios”. Há, também, pistas mais precisas como: "os FP daqui eram todos área da Casa da Torre”. As versões e razões para a sua existência serão aqui discutidas. Por que surgiu e persiste o fundo de pasto? Adicionou-se a essa pergunta um conjunto articulado de relações compreensivas:

- as comunidades nasceram a partir dos currais das Casas da Torre e da Ponte;

- há razões econômicas, fundiárias, ambientais e culturais para a persistência dessas comunidades, combinadas às relações de parentesco e compadrio como elementos facilitadores; $\mathrm{e}$

- desde 1980, a persistência dos FP está associada à organização política, à articulação com instituições, ao apoio governamental e ao seu reconhecimento legal.

A pesquisa, desenvolvida entre 2006 e 2007, fundamentou-se na busca por dados secundários contidos nos relatórios das instituições estatais, em entrevistas com técnicos que participaram do projeto Fundo de Pasto, com agentes pastorais e com as comunidades de FP. Orientou-se pela redução sociológica de Guerreiro Ramos, na qual a busca pelas conexões de sentido da realidade social não pode, de modo algum, ser tratada como um conjunto de fatos desconexos (Ramos, 1965).

\section{BRASIL PLANTATIONS.A.: marcas no campo e sertão brasileiros}

$\mathrm{Na}$ formação histórica das condições socioeconômicas brasileiras, os processos de ocupação foram organizados pelo mercado externo e não por projetos endógenos. Assim, o espaço tornou-se tão somente o local de produção para exportação, independentemente dos custos ambientais e sociais.

Há, no Brasil, uma submissão histórica do projeto de país aos interesses dos países centrais. A formação social ocorre em função da acumulação comercial europeia (Wanderley, 1979a). A formação do Brasil como empreendimento econômico da Europa estabeleceu a classe dos que estão aqui a negócio, senhores de terras, e a dos que estão como insumo do negócio, trabalhadores que servem aos objetivos dos primeiros. Os que chegaram (ou estão) no Brasil a negócio são aventureiros (Holanda, 1978) que, de fato, assumem poucos riscos, pois estão "subterraneamente" sustentados pelo forte "fio da rede mercantil que devora o mundo" (Faoro, 1997, p.105). Repetem, em ciclos, padrões comerciais subordinados (Prado Jr., 1989).

A ideia do país como empreendimento comercial está explícita na expressão "A empresa Brasil”, de Ribeiro (1995). A sociedade se originou e se organizou em função do negócio do açúcar. A coletividade instalada é expressão desse negócio (Prado Jr., 1989). Não foi a colonização que empreendeu a exploração canavieira, mas sim a empresa canavieira que deu origem à colonização.

Interesses "alienígenas" prevalecem e orientam a exploração primária da terra para atender à "vocação oceânica” do Brasil colônia, exportando sua riqueza em favor dos interesses da Europa (Castro, 1967, p.265). A prática de servirem-se da terra como usufrutuários (Holanda, 1978), o sentimento de não-pertencimento dos empreendedores em relação ao Brasil e os deslocamentos humanos internos pela sobrevivência acabaram por se tornar aspectos constitutivos do país.

$\mathrm{O}$ interesse reside em compreender que, durante tais ciclos, principalmente ao final de cada 
um deles, se desenvolveram ideias, formas de vida e de produção distintas, opostas e ou complementares aos projetos hegemônicos. Formas diversas de vida, de produção e de pensamento surgiram nas entrelinhas dos canaviais, nas ruas dos cafezais, nos currais dos sertões, nas hortas, nos mocambos, nas roças de subsistência, nos quilombos, nas fronteiras agrícolas, nos seringais, nos babaçuais, nas “Gerais", e também ficaram nas entrelinhas da história oficial.

\section{CONCENTRAÇÃO, DEGRADAÇÃO E DESCON- TROLE DE TERRAS}

A grande propriedade é o corolário da exploração em larga escala (Prado Jr., 1989) que, por sua vez, é um desdobramento da "Empresa Brasil". Nos 300 anos de colônia, o Brasil se fundamentou, principalmente, na grande propriedade fundiária, na monocultura de exportação e no trabalho escravo (Freyre, 1994; Szmrecsányi, 1990).

A coroa portuguesa transferiu para o Brasil, em 1534, o mesmo regime jurídico da repartição fundiária em sesmarias, instituído em 1375 no reinado de D. Fernando I. Seu objetivo era promover o cultivo e o povoamento das terras incultas ou retomadas dos árabes que ocuparam a península por séculos (Neves, 1998; Garcez, 2001). Em Portugal, a intenção do regime de sesmarias era o de repartir terras. No Brasil, o seu efeito foi inverso: concentrou terras e poder.

No Brasil, os capitães donatários recebiam gratuitamente 50 léguas de costa, obrigando-se apenas ao pagamento de um dízimo à Ordem de Cristo. O período de sesmarias criou a figura dos sesmeiros, senhores e proprietários de terras. Sesmeiro é a denominação dada aos donatários das sesmarias, e também é o mesmo nome dado, em Portugal, aos agentes públicos responsáveis pela repartição de terras (Neves, 2005). Em terras brasileiras, no entanto, esses agentes não eram públicos e podiam agir movidos por interesses próprios. Esse sistema, denominado enfiteuse romana, durou todo o período colonial e pode ser entendi- do como a primeira razão histórica da concentração de terras e da falta de controle sobre terras públicas (Drummond, 1999).

Há crônicos descontrole e desconhecimento de todos os governos do Brasil, do império aos dias de hoje, de suas terras, as chamadas terras públicas (1999). A Coroa ignorava a maior parte das terras mantidas sob seu domínio. Por outro lado, abdicava de qualquer controle sobre elas, na medida em que cedia a súditos de posses, em troca de contribuições anuais, imensas áreas e todo o poder fiscal, militar, judiciário e político exigido para administrá-las. Com a falta de recursos da Coroa, a forma de exercer o seu poder e de garantir a sua parte no negócio se fundava nesse sistema de concessões (Faoro, 1997).

O papel desempenhado pelos senhores de terras, a crescente dependência da coroa em relação a eles e a hipertrofia de suas funções e poderes têm como uma das suas consequências a postergação da reforma agrária (Burstyn, 1990). As doações de terras chegaram a unidades de até 100 léguas quadradas, com diversas delas sendo feitas a um mesmo requerente (Faoro, 1997). A liberalidade desse processo foi tamanha, que, em 1822, já não havia porções de terra para distribuir nas regiões próximas à costa, principalmente no $\mathrm{Su}$ deste e Nordeste do país (1997). Esse fato, associado à decadência dos engenhos, culminou com o fim daquele regime, decretado ainda antes da independência (Resolução Imperial de 17 de junho de 1822).

No que se refere ao domínio de terras, houve um vazio constitucional entre 1822 e 1850. Nesse período, coexistiram sesmarias e posses, o que levou à pressão dos latifundiários sobre os posseiros. Em áreas distantes ou de menor interesse do latifúndio, o vazio legal permitiu também a acomodação de usos costumeiros associados à posse da terra. A possibilidade de obter direito sobre terras por meio da posse e do uso ruiu em 1854, com a regulamentação da Lei Imperial n. 601, conhecida como Lei de Terras. Com ela, as terras ganham caráter de mercadoria e surge a possibilidade de um choque de capitalismo sobre a propri- 
edade fundiária (Wanderley, 1979b), o que, entretanto, não ocorre em virtude da reacomodação do sistema em suas práticas de privilegiar os "bemnascidos". A lei, que visava a modificar as relações com a terra e incentivar a produtividade, tornou-se um simples retrocesso fundiário.

Sem gerar o impacto econômico necessário à transformação dos latifúndios, ela reduziu a possibilidade do acesso popular à terra. A Lei de Terras institucionalizou a ilegitimidade da posse associada ao trabalho e à ocupação. Só eram reconhecidas as propriedades que tivessem registros paroquiais (Decreto Imperial n.1318, de 30/01/ 1854), "embrião capaz de separar o senhor da terra, do mero pretendente ao usucapião" (Faoro, 1997, p.408-409). A noção de propriedade mantém o significado associado à proximidade com o poder e torna ainda mais distante a ação do Estado na democratização do acesso à terra. A terra permanece como simples elemento da natureza, e a propriedade fundiária é abolida em sua expressão econômica (Wanderley, 1979b, p.37-38).

As constituições nunca conferiram grande poder ao Estado para desapropriar terras privadas, fato que contribuiu para a impossibilidade de se enfrentar sua concentração.

Ainda no século XXI, chama atenção a grande quantidade de terras devolutas. Nessas áreas, geralmente vivem posseiros e outros povos, muitas vezes em tensão com outros grupos interessados na sua ocupação. São territórios da desconstrução e reconstrução do campesinato, nos quais surge um padrão camponês de ocupação.

As terras devolutas, indígenas e em unidades de conservação representam $47,12 \%$ das terras disponíveis, cifra pouco inferior aos 49,45\% dos imóveis particulares. Das propriedades com menos de 200 hectares, consideradas como de "agricultura familiar", 64,4\% estão nas regiões Norte, Nordeste e Centro-Oeste, nas quais se encontra uma "grande diversidade de formas de reprodução do campesinato" (Carvalho, 2005, p.68-69). Ainda que muitas dessas pequenas propriedades sejam organizadas como empresas familiares (principalmente nas regiões Sul e Sudeste), o fato é que há uma grande proporção de terras no Brasil nas quais o campesinato se reproduz. Na Bahia, Oliveira (2007) estima 22 milhões de hectares de terras devolutas, $39 \%$ dos 56,7 milhões de hectares do estado, quase o dobro da média nacional.

\section{OCUPAÇÃO DO NORDESTE}

A faixa litorânea, de terras úmidas e férteis (Zona da Mata), presente em todos os estados nordestinos, penetrando em média $80 \mathrm{~km}$ do litoral, foi a área ocupada pelas plantações, pelos engenhos e pelas suas casas-grandes e senzalas.

A introdução da cana-de-açúcar no Nordeste data de 1526, e a paisagem nordestina está impregnada dessa história de "paixão do colonizador" pelo açúcar (Castro, 1967). Em 1584, já havia na região 166 engenhos e, em 1852, apenas na província de Pernambuco havia 642 dessas unidades de produção (Wanderley, 1979a).

As práticas agrícolas dos grandes engenhos do Nordeste eram pouco eficientes, um dos fatores de sua decadência. Em um ensaio de 1834, Miguel Calmon Almeida alertava que os engenhos baianos estavam em decadência e que a indústria ruiria pela baixa qualidade do produto, escassez de mão de obra, competição internacional e falta de combustível (Pádua, 2002).

A produtividade dos engenhos das Antilhas e do Sul dos EUA era de 350 a 400 arrobas de açúcar por enxada/ano, enquanto, na Bahia, ficava entre 100 e 120 arrobas. No século XVIII, ocorre uma baixa de preços, da ordem de $50 \%$, causada pela competição oferecida pela produção das Antilhas holandesas (Galeano, 1994) e Cuba. A renda média per capita teria caído de 30 libras ouro em 1600 para 3 libras ouro em 1800 (Faoro, 1997). Esse cenário se agravou entre 1840 e 1880, com o avanço do derivado de beterraba, que passou de 8 a $48 \%$ do açúcar consumido no mundo (Wanderley, 1979a).

Outro fator determinante para a decadência dos engenhos foi a interrupção do tráfico negreiro (Lei Eusébio de Queiroz) e a transferência de escravos para as regiões auríferas de Minas Gerais e 
para as regiões cafeeiras. As rebeliões de escravos foram outro motivo de decadência. "Morre o açúcar, destruído pelo peso de sua principal força, o escravo” (Faoro, 1997, p.417). No final do século XIX, o Recôncavo Baiano encontrava-se em franca decadência (Pádua, 2002). Para relacionar esse processo de ascensão e queda da agroindústria canavieira ao surgimento das comunidades pastoris, é preciso compreender a face sertaneja desse período.

\section{OCUPAÇÃO DO SERTÃO}

Há poucos registros históricos do processo de ocupação do interior nordestino. Antonil (1982) dedica menos de $5 \%$ do texto à pecuária na caatinga. Entretanto, apesar da centralidade econômica do açúcar, a vastidão dos sertões e a sua ocupação associada à pecuária permitem dizer que há dois nordestes, o agrário e o pastoril (Freyre, 1961).

A criação de gado sempre foi uma atividade econômica subsidiária à cana-de-açúcar (Andrade, 1973). A pecuária, em um primeiro momento da exploração açucareira, foi vizinha aos engenhos, mas, com o tempo, foi adentrando pelo agreste e, finalmente, pelo sertão. O impulso em direção ao interior nordestino teve por base a pecuária, chegando ao sertão principalmente nas regiões tributárias dos grandes centros produtores de açúcar, Pernambuco e Bahia (Prado Jr., 1989). Em 1701, reforçando uma tendência de interiorização da pecuária, a Coroa proibiu a criação de gado numa faixa de 10 léguas a partir da costa. A ocupação dos sertões relaciona-se à entrada pelos vales para estabelecimento de currais. A partir da primeira década do século XVII, seu número cresce (Dantas, 2002). No início do século XVIII, os currais baianos se estendiam pela margem direita do São Francisco e pelos vales dos rios das Velhas, das Rãs, Verde, Paramirim, Jacuípe, Itapicuru, Real, Vaza-Barris e Sergipe (Andrade, 1973).

No agreste, depois nas caatingas e, por fim, nos cerrados, desenvolveu-se uma economia pastoril associada, originalmente, à produção açucareira como fornecedora de carne, de cou- ros e de bois de serviço. Foi sempre uma economia pobre e dependente (Ribeiro, 1995, p.307).

Ainda que, na Bahia, agreste e cerrado também tenham sido afetados por essa expansão pecuária, foi na caatinga que ela se firmou. Apesar de algumas semelhanças, uma diferença crucial entre as ocupações do agreste e da caatinga foi o forte e permanente contato do agreste com os engenhos, enquanto que, nos sertões (caatinga), a pecuária se desenvolveu de modo relativamente independente e isolado. A dependência da ocupação em relação à pecuária é exemplificada na frase de Andrade (1973, p.46) sobre o sertão: "O gado cria o homem aí, em lugar de o homem criar o gado".

A Carta Régia de 1701, segundo Cunha (2002), teria sido uma medida supletiva desse isolamento imposto pela distância. Punia severamente comunicações e qualquer troca comercial daquelas partes dos sertões com as regiões ao sul. Visava a reforçar a relação de subordinação desses sertões aos senhores habitantes da faixa atlântica.

Os vaqueiros eram homens dos senhores. Lideravam alguns poucos ajudantes (em algumas regiões chamados de "fábricas") para cuidar da fazenda. Entre vaqueiros e "fábricas", havia forte hierarquia. Aspecto similar à maior parte dos sistemas pastoris conhecidos no mundo (Ribeiro, 1995).

Havia duas diferentes formas de relação entre sesmeiro e vaqueiro nos currais. Nos melhores pontos, os sesmeiros mantinham um vaqueiro pago com a quarta de bezerros e potros, sistema também denominado "sorte". Nesse sistema de produção, cada vaqueiro tinha o direito de apartar para si uma em cada quatro crias (Andrade, 1973), podendo apascentar os seus animais sem distinção de tratamento ou área em relação aos animais do patrão. Esse sistema de pagamento contribuiu para que muitos acumulassem recursos para se tornarem eles mesmos "fazendeiros". A segunda forma de relação era o sistema de enfiteuse, no qual os sítios com uma légua em quadro eram cedidos em troca de 10 mil réis ao ano, pagos pelos foreiros (Antonil, 1982). 
No Nordeste, as concessões coloniais de terras foram maiores, dando origem a imensas casas senhoriais, como Casa da Torre, Casa de Sertão, Casa da Ponte, Casa do Sobrado, Casa de João País, Casa de Vieira (Faoro, 1997). "Sendo o sertão da Bahia tão dilatado, como temos referido, quase todo pertence a duas das principais famílias da mesma cidade, que são a da Torre, e a do defunto mestre de campo Antonio Guedes de Brito" (Antonil, 1982, p.200). Nessas imensidões, eram imprecisos os limites de terras entre as Casas. As únicas referências às dimensões alcançadas por elas são as de Antonil (Neves, 1998).

As relações entre sesmeiros e vaqueiros repetem os padrões em que um poder central mantém e se mantém em função da reciprocidade com poderes locais (Faoro, 1997; Bursztyn, 1990). Com a decadência da pecuária, essas relações se tornaram mais instáveis e voláteis. Os movimentos desses poderes locais sempre foram determinantes para a relativa autonomia dos posseiros; quanto mais presentes e poderosos os senhores, tão mais difíceis e incertas as suas condições.

\section{TERRAS E GENTES: formação de um campesinato sertanejo} to econômico movido por interesses exógenos (Prado Jr., 1989; Holanda, 1978; Freyre, 1994; Ribeiro, 1995) passou por inúmeros ciclos, ao fim dos quais sempre restava uma massa de gente que a eles "aderira" (livre ou forçosamente) como insumo da produção. Esta massa dá origem aos grupos sociais do campo. Há processos de criação do campesinato, pois, ao mesmo tempo em que o capital o destrói em um lugar, o recria em outro (Fernandes, 2001). As mudanças e avanços do capitalismo no campo sempre deixam espaços, dobras e intervalos nos quais famílias continuam ou passam a viver, pouco participando do sistema econômico.

Em um primeiro momento, quando da ascensão de um ciclo econômico, grandes proprietários engolem pequenos e empurram posseiros para as fronteiras (Carvalho, 2005). Quando da decadência, as pequenas propriedades se expandem dentro de seus próprios limites (Silva, 1980). Essa reprodução do campesinato se dá tanto nas próprias áreas de fronteira quanto nas áreas menos interessantes para o desenvolvimento da agricultura capitalista (terras áridas, menos férteis, mais isoladas, menos estruturadas). Os sítios dos posseiros e o próprio conceito de sítio, em algumas regiões do Nordeste, se unificam sob a ideia de “terra fraca” (Meyer, 1979).

Das quatro empresas constitutivas do Brasil, a terceira, na qual se desenvolveram as microempresas de produção de gêneros de subsistência e a criação de gado, é, segundo Ribeiro (1995), aquela que gestou as células do povo brasileiro. Elas constituíram, sobretudo, um criatório de gente (p.161).

As relações não-capitalistas produzidas e produtoras do contexto camponês brasileiro sempre estiveram subordinadas à dominação do capital. As estratégias de subordinação, que se dão no sistema econômico, são a cessão das áreas marginais (terras menos férteis e locais com climas secos, "naturalmente" deixados de lado pela agricultura capitalista) e a comercialização de seus produtos a preços aviltantes. Em uma cadeia agroindustrial, o camponês sempre se insere no elo menos rentável.

Há também a subordinação pela via do trabalho, com as diárias mal pagas que o camponês vende, sazonalmente, nas safras das grandes fazendas de sua região ou mesmo migrando. Subconsumo, jornadas ampliadas, trabalho gratuito da família são estratégias que viabilizam a reprodução social desse campesinato que se torna, assim, semiproletarizado (Cotrim, 1991).

No Nordeste, o termo camponês tem duas acepções. Uma que inclui os assalariados rurais e outra, mais restrita, que se refere àqueles que não foram totalmente expropriados dos seus meios de produção (Andrade, 1989). A gênese do sertanejo se ajusta a essa segunda acepção do campesinato nordestino que, em algumas regiões, manteve a posse da terra em comunidades pastoris, nas quais se incluem os Fundos de Pasto. 
O semiárido nordestino é o contexto de formação do sertanejo, povo associado ao pastoreio do gado trazido de Cabo Verde e que foi desenvolvendo vestimentas, culinária, modos de vida, organização familiar, estrutura de poder, visão de mundo e religiosidade típicos (Abreu, 1963; Andrade, 1973; Cunha, 2002). A interiorização da pecuária pelo sertão gerou uma verdadeira "civilização do couro" (Abreu, 1963).

A relativa liberdade desses vaqueiros, ainda que em regime de servidão, diferia em muito das condições dos engenhos. Provavelmente, segundo Ribeiro (1995), ela atraiu brancos pobres e índios mestiços vindos das faixas litorâneas. Junto ou próximos aos vaqueiros, havia também alguns poucos rendeiros, gente livre, sem acesso à terra, que criava seus animais nas propriedades de outros (Dantas, 2002). Eram grupos de dez a doze homens, índios, mestiços, escravos em fuga, foragidos da justiça, aventureiros procurando "liberdade e desafogo" (Prado Jr., 1989 p.45).

\section{APOSSAMENTO COLETIVO E PASTORIL DAS TERRAS DEVOLUTAS DO SERTÃO}

E o sertão é um vale fértil. É um pomar vastíssimo, sem dono. (Cunha, 2002, p.43). Abriram-se desde o alvorecer do século 17 , nos sertões abusivamente sesmados, enormíssimos campos, compáscuos sem divisas, estendendo-se pelas chapadas em fora. [...] Esta solidariedade de esforços evidencia-se melhor na "vaquejada", trabalho consistindo essencialmente no reunir, e discriminar depois, os gados de diferentes fazendas convizinhas, que por ali vivem em comum, de mistura, em um compáscuo único e enorme, sem cercas e sem valos (2002, p.83).

Nessas afirmativas de Euclides da Cunha, veem-se duas percepções diferentes sobre o mesmo processo de ocupação, a do sertão sem dono e a dos pastos sesmados e partilhados em compáscuos. A falta de explicitação da diferença entre "sem dono" e "partilhados em compáscuos" é uma das geratrizes da indefinição em que ainda se encontram as áreas apossadas coletivamente nos sertões.

Registre-se que, até 1930-1940, os travessões eram as únicas divisões de terra de todos os ser- tões, além, é claro, dos pequenos cercados dos roçados dos vaqueiros. Entretanto, desde aquelas décadas, o advento do arame farpado tem facilitado a prática dos grandes fazendeiros de cercar as melhores áreas para formar as "mangas" para o seu gado. Durante os séculos XVIII e XIX, a decadência dos engenhos esvaziou progressivamente a economia do sertão. Os senhores de currais, diferentemente dos senhores de engenhos, não moravam em suas terras. O vazio econômico reforçou o isolamento dos currais dos sertões entre o século XIX e a segunda metade do século XX. O fracionamento das grandes sesmarias das Casas da Torre e da Ponte iniciou-se no final no século XVIII (Cotrim, 1991). O período entre 1830 e 1844 é marcado pela rápida comercialização das terras das sesmarias da Casa da Ponte, justificada pelos altos custos de manutenção da família, que passara a viver na Inglaterra. O desmanche da Casa da Torre iniciou-se ainda na segunda metade do século XVIII, com as vendas feitas pela viúva do Capitão Garcia D’Ávila Pereira para diferentes compradores (Dantas, 2002).

Assim como não eram rigorosos os limites entre as duas casas e entre as sesmarias, as escrituras que decorreram de sua dispersão são igualmente imprecisas. Essas áreas eram vendidas em termos de contos de réis e os formais de partilhas valiam frações de contos de réis. São essas referências que se encontram entre os raros documentos em mãos das comunidades pastoris do sertão. Muitas posses estabelecidas por vaqueiros e foreiros foram mantidas sem contestação de sesmeiros. Durante o século XX, nas áreas mais férteis, povoadas e próximas ao litoral nordestino, a tendência foi a total expropriação e o assalariamento dos trabalhadores. No entanto, o avanço do capitalismo não foi pleno nas terras nordestinas devolutas e pouco povoadas (Andrade, 1989). É sobre essas terras que se estabeleceram comunidades pastoris e onde persistem, no século XXI, fortes processos de grilagem.

Até 1850, predominava, na caatinga, o pastoreio comunitário, regrado pelo direito costumeiro, no qual o conceito de posse era igual ao de domínio. Os limites entre as fazendas e sítios eram 
reconhecidos por consenso entre os ocupantes e os confrontantes (Cotrim, 1991). A partir desse período, desenvolve-se uma dicotomia entre os grandes pecuaristas que constituíam grandes fazendas de gado e os caprinovinocultores baseados em sítios camponeses (1991).

Os conflitos se deram, até as primeiras décadas do século XX, sem que houvesse grandes cercamentos de áreas. Prevalecia o sistema da "solta” para bovinos e caprinos. Há várias referências aos tempos em que os animais pastavam sem qualquer limite, usando todas as terras da região.

Os cercamentos de áreas do sertão iniciaram-se somente a partir dos anos 1920, pela "modernização” da pecuária extensiva e especulação de terras. Foi um dos processos de transformação localmente mais significativos, pois avançou sobre áreas ocupadas por posseiros. A pressão fundiária mediante a grilagem, por meio da privatização de terras comuns e do fechamento dos espaços da "solta” do gado, tem ameaçado os grupos de tradição pastoril (Carvalho, 2005).

A indução pelo Instituto Nacional de Colonização e Reforma Agrária (INCRA) do parcelamento individual das terras foi um dos principais fatores de extinção das formas de apropriação coletiva no vale do Guaporé, em Rondônia (Carvalho, 2005). As singularidades dos apossamentos de várias populações, como seringueiros, quilombolas e ribeirinhos, são ignoradas nos processos de regularização fundiária (Benatti, 2005). A preocupação com as peculiaridades das comunidades pastoris compôs a justificativa do primeiro projeto de regularização fundiária voltado para elas (CAR, 1982).

De um modo geral, esses apossamentos coletivos enfrentam sérias ameaças à sua reprodução. Tratando-se de áreas marginais para a agricultura capitalista, muitas vezes a grilagem de terras tem fins meramente especulativos. No trato do problema fundiário do sertão, ainda que, em algumas regiões, a agricultura irrigada tenha tomado áreas com perspectiva moderna e capitalista, predomina a especulação de terras.

\section{POSSEIROS E BODES NA CAATINGA BAIANA: formação dos fundos de pasto}

A compreensão entre as comunidades pastoris da Bahia é de que sua realidade é imemorial. No dizer de um de seus integrantes: "Nem sei falar quando começou, existiu toda a vida. O que aconteceu foi que as áreas foram diminuindo, mas Fundo de Pasto sempre existiu, as terras eram devolutas, criavam bode que é duro na queda e aguenta seca".

Apesar da exclusão ou subordinação dos camponeses, a não-ocupação, de facto, pelos sesmeiros permitiu que remanescentes desses vaqueiros e "fábricas" fossem progressivamente ocupando essas terras como posseiros, reconhecidos ou não. Aos vaqueiros dos currais sempre foi permitido criar pequenos animais: cabras, carneiros e porcos. A divisão entre fazendas e sítios, sitiantes ou posseiros e proprietários, fortes e fracos, nascida após a Lei de Terras de 1850, era também representada na caatinga pela dicotomia gado e bode. Em algumas regióes, entre o século XIX e a primeira metade do século XX, essa dicotomia pendeu para bode, sítios e posseiros.

Entre 1970 e 1980, enquanto a pecuária não avançou, tendo mesmo decaído, a caprinovinocultura cresceu significativamente. A área de pastagem decresceu, uma vez que caprinos e ovinos são criados em sistema extensivo, sem limites de áreas de estabelecimentos. Freyre (1961, p.80) parece descrever um Fundo de Pasto: "a cabra do nordestino, criada como é, sem a mínima vigilância, num território onde as cercas não são feitas para dividir terrenos, mas unicamente para resguardo dos cercados ou pequenas plantações". Uma descrição feita por Andrade (1973) sobre o modo de vida sertaneja coincide com o padrão de ocupação atual das comunidades pastoris do sertão da Bahia:

As grandes distâncias e as dificuldades de comunicação fizeram com que aí se desenvolvesse uma civilização que procurava retirar do próprio meio o máximo, a fim de atender às suas necessidades. [...] Lavouras de ciclo vegetativo curto - feijão, fava, milho, etc. - eram confinadas 
por cercas de varas ou de pedras a fim de impedir a danificação provocada por animais. (Andrade, 1973, p.183)

É importante observar que, entre Freyre e Andrade, não se encontra a expressão Fundo de Pasto, mas, repetidamente, eles se referem à criação de cabras "à solta" na caatinga, o que permite inferir ser essa uma condição comum na região, ao menos no período em que fizeram seus estudos, entre 1920 e 1950. Na Bahia, destacadamente no Sertão Norte, além das áreas de pastoreio, registra-se o uso de outros recursos comuns como as aguadas e áreas para extrativismo de frutas, madeira, mel e caça. A comunidade sertaneja, em geral, possui laços de parentesco, compadrio ou proximidade e realiza o manejo desses recursos comuns de modo partilhado, com trocas de favores e mutirões.

A relação das atuais comunidades pastoris com os antigos currais fica evidente ao se comparar o mapa das casas senhoriais com os municípios onde hoje se encontram Fundo de Pasto. Um dos documentos de terra mais antigo em posse dos moradores descreve o desmembramento da área no livro de Tombo da Casa da Torre, de 27 de agosto de 1828 (Garcez, 1987). São muitas as áreas de Fundo de Pasto que pertenciam à Casa da Torre, e sua ligação com os currais é descrita por Antonil como sempre instaladas em paragens com disponibilidade de água, o que é reforçado pelos nomes das comunidades, quase a metade deles associados a esse elemento: tanque, lagoa, poço, barreiro, riacho, olho d'água, várzea, alagadiço, bica, brejo, vereda.

A maior parte das comunidades pastoris localiza-se em terras devolutas, originadas de grandes fazendas desmembradas ou compradas das sesmarias originais. Essas comunidades, frequentemente constituídas por famílias de descendentes dos herdeiros dessas "fazendas-mãe”, não possuem qualquer documentação que registre a posse, exceto raros recibos de compra e venda ou formalizações de partilha de heranças. Esses documentos, quase sempre em mãos de pessoas mais velhas, são os únicos existentes de comprovação de posse das terras.

\section{RAZÕES DA CONFIGURAÇÃOE PERSISTÊN- CIA DAS COMUNIDADES PASTORIS BAIANAS}

Por que essa ocupação se configurou e persistiu após o fim dos currais? As razões explicativas são dúbias e não-excludentes. O estudo da literatura e de relatórios, as entrevistas com técnicos das instituições próximas e com as famúlias das comunidades pastoris sugerem sete diferentes interpretações:

- Razão ambiental: a baixa densidade populacional, no contexto de pobreza dos recursos naturais, reforçada pela baixa pluviosidade, teria conduzido a formas de exploração extensivas e sobrepostas (Andrade, 1973; CAR, 1982; Sabourin; Marinozzi, 2001). Para muitos, essa forma de ocupação seria mais preservadora, mais econômica, mais estável e resistente às variações climáticas. Acrescenta-se o argumento da adequação genética do gado pastoreado pelos sertanejos que, vindo de Cabo Verde, adaptava-se ao regime extensivo, procurando a própria comida e as aguadas, prescindindo de estabulação (Ribeiro, 1995). O mesmo se aplica ao desenvolvimento do bode "pé-duro", adaptado às condições de pastoreio solto na caatinga. A adaptação do bode foi experimentada longamente nos currais, uma vez que a propriedade e a criação de pequenos animais eram autorizadas aos vaqueiros pelos sesmeiros.

- Razão ibérica: a persistência estaria na matriz cultural, fruto da herança da forma comunal de ocupação das terras em Portugal e Espanha. As comunidades pastoris do sertão baiano se relacionariam aos "baldios", áreas de terra livre disponíveis para os camponeses em Portugal.

- Razão antieuropeia: idealiza o caráter indígena e negro como solidários, em oposição ao caráter europeu. Refere-se às tradições comunitárias indígenas, reforçadas pelos laços de solidariedade intrínsecos aos quilombos. Parte da ideia de que a noção de propriedade privada era estranha aos não-brancos e teria, assim, se reproduzido entre a população mestiça dos sertões, a partir de seus 
elementos indígena e africano.

- Razão indígena: a configuração das comunidades pastoris do sertão seria uma adaptação dos territórios de caça das aldeias. Os caprinos teriam tomado o lugar da caça quando do aldeamento de indígenas. A tradição indígena, de vida e produção comunitárias, teria sido reforçada por missionários da Igreja (Cotrim, 1991), que talvez buscassem reeditar as primeiras comunidades cristãs. Essa hipótese não encontra apoio em Ribeiro (1995), que reconhece ter havido uma "substituição" dos territórios tribais de caçadas por áreas de pastoreio pelos vaqueiros, mas sustenta que essa mudança teria sido de tal modo conflituosa e violenta, que marcou mais um afastamento entre vaqueiros e indígenas que uma mútua influência.

- Razão socioeconômica: a existência de comunidades pastoris no sertão seria resultante da sua pobreza. Essas terras teriam sido "esquecidas” por causa do seu baixo potencial produtivo e da baixa valorização econômica (Cotrim, 1991). Com a decadência dos currais, “abandonados” à própria sorte nos sertões, os remanescentes teriam sido induzidos à vida comunitária e à partilha. Essa hipótese pode assumir uma versão marxista, segundo a qual essas comunidades "pré-capitalistas" não configuraram um sistema de produção para acumulação privada e primitiva de capital e, assim, não individualizaram suas terras.

- Razão da falta de ordenamento fundiário: a impossibilidade de reconhecimento, regularização e titulação da propriedade familiar, seja pela compra e venda de terras ou pelo reconhecimento estatal da posse, induziu a sua não-discriminação individualizada Após a decadência dos currais (1750-1850), os vaqueiros e posseiros não se fizeram donos, mas apenas usufrutuários da terra e, portanto, sem direito à apropriação individual. Essa hipótese é reforçada pela ideia de que, além da dificuldade, havia um grau de desinformação sobre direitos, o que induziu a apropriação coletiva das terras (Cotrim, 1991); e

- Razão clânica (sociocultural): o relativo isolamento das famílias de vaqueiros acarretou uma ocupa- ção pelo simples crescimento vegetativo. Em virtude da natureza da produção pecuária e dos modos de repartição de benefícios, esses indivíduos nunca reuniram razões para dividir as terras por unidades familiares. A não-divisão seria uma estratégia de sobrevivência do grupo e um prosseguimento do modo de produção dos currais.

Dentre todas, a explicação clânica (sociocultural) parece dominante frente às outras que, em geral, estão subordinadas a ela. A manutenção das terras indivisas só aconteceu porque os conflitos internos eram (e continuam sendo) passíveis de solução no âmbito comunitário-familiar; as comunidades são predominantemente formadas por herdeiros e seus descendentes, parentes em diferentes graus. As razões ambientais, econômicas e fundiárias também são factíveis, podendo, em diferentes graus, terem se somado para fortalecer o modo Fundo de Pasto de uso e ocupação. As hipóteses de cunho étnico-cultural (indígenas e antieuropeias) são mais difíceis de avaliar e não parecem muito significativas por duas razões: a apontada por Darcy Ribeiro quanto à não-assimilação, mas sim o enfrentamento dos índios pelos vaqueiros; e a configuração aberta dos grandes currais não ter sido opção das comunidades ou dos vaqueiros, mas uma contingência das sesmarias. De qualquer modo, pode-se agregar à explicação o fato de a ascendência ser de camponeses pobres, portugueses, indígenas ou negros. Todos eles, camponeses pobres, independentemente de qualquer influência cultural direta, nunca tiveram propriedade privada de terras e não conseguiram superar essa condição.

\section{CONFLITOS E RESISTÊNCIA AOS ENCLOSURES}

Houve a consolidação de algumas formas de ocupação camponesa, tanto por um gap da ação do Estado quanto pela decadência econômica das duas "Casas": da Torre e da Ponte. A partir do final do século XIX, começa, em escala mundial, o avanço do cercamento de terras com a tecnologia 
do arame farpado, o que impactou fortemente as Américas (Razac, 2000). A difusão do arame contribuiu para maior apropriação de terras e recursos naturais, levando ao fim de sistemas pastoris comunitários que levavam nomes como "solta", "larga” ou "largueza" (Carvalho, 2005). Esse avanço sobre terras comunais ocorre em todas as regiões em que elas persistiram, como nas terras dos "geraizeiros" do Jequitinhonha, das chapadas do Espinhaço, no Piauí, nas terras chamadas "solta larga”, no Mato Grosso, no vale do Guaporé, em Rondônia, nos babaçuais e carnaubais de Piauí e Maranhão (Andrade, 1989; Galizoni, 2000; Carvalho, 2005). Trata-se de um fenômeno comparável ao processo dos enclosures ingleses, quando a mercantilização das terras e do trabalho impulsiona um avanço sobre as áreas comunais (Polanyi, 2000).

A "modernização" da pecuária, iniciada nos anos 1920, deflagrou o avanço sobre as áreas ocupadas por posseiros do sertão e seu cercamento. Grande parte dos conflitos agrários envolvendo os Fundos de Pastos surgiu por influência do Estado como agente planejador do território (Alcântara; Germani, 2004). A partir de 1950, a política de integração do interior do governo de Otávio Mangabeira (1948-1951) reforçou a pecuarização e a concentração de terras (Freitas; Rocha; Mello, 1984). Na década de 1970, a pecuária ganha novo impulso, com o crédito subsidiado e a abertura de agências bancárias no interior, facilitando e incentivando as transações. A ampliação do crédito e do sistema bancário coincide com os registros dos primeiros grandes conflitos entre os Fundos de Pasto e os fazendeiros.

A partir da década de 1970, houve cinco eixos articulados de pressão sobre as comunidades pastoris do sertão baiano: 1) pressão ambiental, pela degradação da caatinga; 2) pressão política, com a criação de leis municipais obrigando o cercamento de áreas (leis dos quatro fios); 3) pressão fundiária, ocasionada pela grilagem de terras; 4) pressão econômica, pela valorização das terras; e 5) pressão técnica, em virtude das propostas de modernização da agricultura e da ampliação da pecuária.

Os representantes das comunidades de Fun- do de Pasto e das organizações associadas referemse ao "Projeto Sertanejo" (década de 1980) e a outros programas do governo da Bahia como processos de apoio e financiamento para aquisição e cercamento (grilagem) de terras. O aumento da vulnerabilidade das populações locais e de sua consequente desterritorialização decorre também dessas ações de governo (Oliveira; Rothman, 2007). A partir do final da década de 1970, as comunidades pastoris estavam sendo impedidas de criar ovinos e caprinos, base de sua atividade econômica e de subsistência, em virtude da crescente apropriação privada da terra, apoiada por leis municipais da mesma época, denominadas popularmente de "lei do pé alto" ou "lei dos quatro fios". Elas favoreciam a ocupação de terras por grandes pecuaristas de gado de corte, criado em regime extensivo, em detrimento da ocupação vigente, no regime de "bode solto", característico dos Fundos de Pasto.

A Lei municipal de 4 de maio de 1981 de Paulo Afonso impunha ameaças que se somavam a outras enfrentadas pelos caprinocultores comunitários:

Art. $1^{\circ}$. A criação de caprinos e ovinos no município deverá ser em área cercada e os rebanhos guardados e vigiados com cuidado preciso a fim de evitar prejuízos em propriedades alheias.

Art. $2^{\circ}$. Aos agricultores e pecuaristas fica assegurado o direito de construírem cercas para a proteção de suas lavouras ou para o critério do gado vacum com apenas 3 ou 4 fios de arame farpado.

O terceiro artigo da mesma lei previa multas para os danos causados por animais soltos. Leis similares se multiplicaram, no início dos anos 1980, por todos os municípios onde há ou havia comunidades pastoris.

A resistência contra essa lei era parte de uma luta para a continuidade da criação de caprinos no sistema "bode solto", cujo fim comprometeria a reprodução social das comunidades. A criação presa implica em estruturação física (capril) e dependência de arraçoamento por ração produzida na caatinga ou adquirida no mercado.

A luta ganhou vários nomes regionais: "bode solto", "Fundo de Pasto", "luta pela solta”. Em 
muitas regiões, Fundo de Pasto sempre foi a expressão utilizada para designar o pastoreio comunitário, embora fosse ignorada em várias outras. A expressão se origina no fato de os animais se afastarem das pequenas áreas individuais, próximas às casas, e se embrenharem no interior da caatinga, em amplas e distantes áreas coletivas: os fundos de pasto. Não havia denominação comum, identidade ou organização política dessas comunidades antes dos conflitos. Foi o avanço das lutas que levou à adoção desse nome comum: Fundo de Pasto. Em algumas regiões, o nome Fundo de Pasto é corrente e imemorial. Declara-se existir desde o começo do mundo, ou que existe desde antes do tempo dos avós. Ou então que "Fundo de Pasto, com a gente criando solto, todo mundo junto, nasceu com o mundo.” (SEPLANTEC/CAR, 1983). Em outras, a denominação é apontada como bem recente. "A gente veio descobrir o que era Fundo de Pasto quando se organizou. [...]. Se organizou por causa dos conflitos com mineradoras, latifundiários. [...] A discussão tem só 30 anos”, declara um representante dos Fundos de Pasto. A depender do grupo, a discussão é ainda mais recente: "Esta conversa de Fundo de Pasto é nova, a gente aqui só falava em criar solto; foi de uns 15 anos pra cá que vieram com esse nome”.

A atuação em favor dos Fundos de Pastos por parte de instituições do governo começou no início dos anos 1980. O projeto Programa de Desenvolvimento Rural Integrado (PDRI-Nordeste) refere-se aos Fundos de Pastos como áreas de pastoreio comunitário e de atividades extrativas, asseverando a sua importância para sobrevivência em uma região pobre. Registra também o posicionamento dos grupos de famílias que reclamam a posse das áreas e aponta a tendência à sua "extinção" em função dos cercamentos com fins especulativos, da destruição da flora nativa e da carvoagem.

Os primeiros relatos técnicos descreviam essas áreas da seguinte maneira: "a caprinovinocultura [...] é explorada de forma comunitária nos chamados FP, onde um grupo de famílias reclama a posse de uma área mais ou menos delimitada, sem cercas [...]." e "sendo a grande parte da área utili- zada para o pastoreio comunitário, com a criação "solta" na caatinga, e para o desenvolvimento de atividades extrativas.”(PDRI-Nordeste, 1982, p.48).

Uma política de regularização fundiária que desconheça as peculiaridades e aspirações dessas comunidades traria "sérios transtornos à sobrevivência das mesmas” (CAR, 1982). A preocupação com essas formas regionais típicas de ocupação justificou o Projeto Fundo de Pasto. Financiado pelo Banco Interamericano para a Reconstrução e o Desenvolvimento (BIRD) e pelo Banco Mundial, visava a identificar áreas comunitárias de pastoreio, estudar viabilidade econômica e jurídica e controlar as tensões sociais.

Os relatórios produzidos no âmbito do Projeto Fundo de Pasto são, invariavelmente, favoráveis à manutenção dessas áreas comuns. Os representantes do governo baiano, quando identificam o contexto, demonstram perceber uma urgência na ação governamental.

Assim, a resistência comunitária e a abertura do governo baiano culminaram no reconhecimento e na regulamentação de áreas individuais e coletivas, situando oficialmente os Fundos de Pastos como personagem jurídico de legalização de terras de comunidades pastoris.

Um importante passo na resistência das comunidades pastoris e consolidação da categoria dos Fundos de Pastos foi o artigo 178 da Constituição baiana de 1989, que reconhecia a existência de formas de uso comunitário da terra. Várias instituições, como a Comissão Pastoral da Terra (CPT), declaram que as suas ações em defesa dos Fundos de Pastos se fortaleceram a partir desse artigo da Constituição.

Ao reconhecer que tais ocupações são caracterizadas por uma “atipicidade”, mesmo no Projeto, já ficava claro que havia necessidade de uma "saída legal não-convencional” para o processo de sua regularização. Essa saída foi encontrada na regularização coletiva por meio de uma sociedade civil, sem fins lucrativos, à qual estivessem filiados todos os interessados.

O primeiro passo do Projeto Fundo de Pasto era ao identificar e medir as áreas, discriminar 
as terras devolutas e as particulares. O segundo era garantir, mediante decreto, a reserva das terras públicas identificadas para o atendimento dos interesses socioeconômicos das comunidades. A base jurídica para o estabelecimento desses "condomínios de pastagens" foi o compáscuo, modo coletivo de ocupação de pastos, previsto e tratado no artigo 646 do Código Civil Brasileiro. Nessa proposta "experimental”, o compáscuo havia de ser não o modo ou a forma jurídica da atividade, mas o objeto da sociedade civil sem fins lucrativos que o assumiria. A fórmula da legalização em nome de todos já havia sido usada anteriormente para a solução de conflito nascido da reação de uma comunidade a um processo de grilagem em larga escala (Garcez, 1987).

O processo de regularização prosseguiria, a partir daí, mediante duas formas de legalização. Quando da não-existência prévia de sociedade civil organizada como associação, as áreas ocupadas comunitariamente eram regularizadas em nome das pessoas que receberam áreas individuais e que se comprometiam à imediata doação de suas glebas comuns à sociedade à qual se filiariam. Quando da existência prévia de associações, as áreas comunitárias eram regularizadas globalmente, sob a forma de doação em nome dessas entidades.

Os órgãos de governo introduziram um padrão de estatuto de associação de Fundo de Pasto. Em seus artigos, se estabelecem os mecanismos jurídicos, como a sociedade civil por quotas (condomínio), a quota-parte, a vedação do direito de apropriação individual de aguadas e equipamentos comuns e a inalienabilidade das terras comuns.

Essa ação do Estado sobre os Fundos de Pasto não deixou de ser tardia. Certamente, eles chegaram a ser mais numerosos, sendo progressivamente ameaçados pela expropriação de terras e pela extração de madeira e de outros itens. São comuns as declarações: "antes era tudo Fundo de Pasto" ou "todo mundo criava solto". Relatam-se conflitos de terras iniciados na década de 1940.É interessante perceber que, ainda ao final da década de 1980, predominava o nome "fazenda" e que, a partir dos anos 1990, paulatinamente, prova- velmente em função das lutas e do surgimento de novos atores, as denominações passam a ser "associação" ou "comunidade". Não obstante, muitas das localidades não resistiram aos conflitos e nelas não se registra mais a presença de áreas típicas, que passam a ser denominadas de Fundo de Pasto.

\section{CONSIDERAÇÕES FINAIS}

No sertão da Bahia, em vastas áreas, mas com populações não tão numerosas, configuraram-se, a partir das sesmarias, sistemas agrossilvipastoris com uso comunal de terras. A origem dessas comunidades pastoris está relacionada aos currais das Casas da Torre e da Ponte: há uma coincidência geográfica, a mesma associação com as aguadas, a antiguidade das comunidades e os formais de partilha que datam da primeira metade do século XIX, período de desmembramento das sesmarias. As comunidades são compostas por familiares, e há inúmeras práticas de compadrio. As identidades, os acordos e o diálogo são reforçados por essas relações. A documentação frágil e o pouco interesse em fragmentar as áreas dos "clãs" em unidades familiares contribuíram para a manutenção do regime comunal.

O desinteresse econômico e estatal por essas áreas, ao longo do século XIX e início do século XX, favoreceu a consolidação desse padrão camponês de ocupação e uso das terras do sertão baiano, ainda sem uma identidade ou organização regional. Várias gerações se sucederam, produzindo e reproduzindo um padrão de ocupação pastoril e comunal. O longo prazo de maturação dessa ocupação - mais de duzentos anos, em alguns casos - favoreceu um posicionamento firme por parte das comunidades, que passam a se perceber e a se afirmar como detentoras de direitos históricos. O passado não foi determinístico. A partir das décadas de 1970 e 1980, por iniciativa de fazendeiros estimulados por leis municipais, iniciouse um período de conflitos que levaram à organização das comunidades pastoris e à formulação de sua categoria. Um projeto do governo (Projeto Fun- 
do de Pasto) e um artigo da Constituição baiana definiram uma denominação geral que passou a caracterizar um grande número de grupos que ocupam vastas áreas. Estavam criadas as condições iniciais para institucionalização dessa categoria, não como mera estratégia discursiva ou resultado determinado do passado, mas como a emergência de uma nova identidade.

Trata-se da politização da vida cotidiana e das práticas rotineiras no uso da terra que fazem emergir novas identidades, como já apontavam Carvalho (2005) e Almeida (1997), ao se referirem a articulações e denominações coletivas que decorreriam de processos de mobilização política no espaço rural.

Assim, três fatores concorreram de modo sinérgico para a preservação dessa forma de ocupação no sertão baiano: o próprio uso comunal social e historicamente constituído, a organização política das comunidades em outras escalas (regional e estadual) e a fresta no muro técnico-burocrático do Estado, aberta na ação dos órgãos responsáveis pela questão da terra e pela inclusão dos Fundo de Pasto na Constituição. O uso comunal das terras conferiu uma coesão entre as comunidades, o que resultou em agilidade na mobilização e em maior resistência aos processos de grilagem e cercamento das áreas comuns. A articulação entre comunidades, surgida no bojo do conflito, ampliou o poder de resistência regional e a visibilidade estadual. A fresta na tecnoburocracia do Estado permitiu que essa resistência se convertesse em maior estabilidade na ocupação camponesa e comunal das terras.

O Estado, tradicionalmente contrário à ocupação camponesa, favoreceu-a em dois momentos. Primeiramente por omissão, no século XIX, ao se ausentar da regulamentação das terras durante período de fragilidade econômica dos latifúndios sertanejos (1822-1850). Em seguida, ao agir, a partir de 1980, com políticas, projetos e leis, tanto estaduais como federais, favoráveis aos Fundos de Pasto. Essa positividade foi fruto de circunstâncias da década de 1980 (funcionários mobilizados e comunidades resistentes), e não de alguma altera- ção profunda da perspectiva política do Estado.

O interessante paradoxo que se revela é que, a tendência homogeneizante do campo brasileiro induz a emergência de novas identidades. Cria-se a impressão do aumento da diversidade, ainda que essas novas categorias sejam unidades circunstanciais da resistência.

(Recebido para publicação em outubro de 2009) (Aceito em abril de 2010)

\section{REFERÊNCIAS}

ABREU, Capistrano de. Capítulos de História Colonial: os caminhos antigos e o povoamento do Brasil. Brasília: Ed. UNEB, 1963. $402 \mathrm{p}$.

ALCÂNTARA, Denilson M. de; GERMANI, Guiomar Inez. A produção do espaço a partir da resistência. Disponível em:www.lead.uerj.br/VICBG-2004/Eixo1/e1\%20364.htm. Acesso em: 29 nov. 2004.

ALMEIDA, Alfredo Wagner Berno de. Pluralidade de atores sociais e diversidade dos critérios político-organizativos em face da internacionalização dos mercados. In: A luta pela terra: a Comissão Pastoral da Terra 20 anos depois. São Paulo: Paulus, 1997. p.113-121.

ANDRADE, Manuel Correia de. A terra e o homem no Nordeste. 3.ed. São Paulo: Brasiliense, 1973. 252 p. (Série princípios).

Lutas camponesas no Nordeste. 2.ed. São Paulo: Ática, 1989. 64 p.

ANTONIL, André João. Cultura e opulência do Brasil: texto confrontado com o da edição de 1711. 3.ed. Belo Horizonte: Editora Itatiaia; São Paulo: EDUSP, 1982. 240 p.

BENATTI, J. H. Posse coletiva da terra: um estudo jurídico sobre o apossamento de seringueiros e quilombolas. Disponível em: www.dhnet.org.br/direitos/sos/terra. Acesso em: 21 dez. 2005.

BURSZTYN, Marcel. O país das alianças: elites e continuísmo no Brasil. Petrópolis: Vozes, 1990. 140 p.

CAR-PDRI NORDESTE. Projeto Fundos de Pasto: aspectos jurídicos e socioeconômicos. Salvador: CAR, 1982.

CARVALHO, Horácio Martins de. O campesinato no século XXI: possibilidades e condicionantes do desenvolvimento do campesinato no Brasil. Petrópolis: Vozes, 2005. $405 \mathrm{p}$.

CASTRO, Josué de. A geografia da fome: a fome no Brasil. 2. ed. Rio de Janeiro: O Cruzeiro S.A., 1967. 334 p.

COTRIM, Dione Vinhas Nascimento. O pastoreio comunitário em Uauá: uma expressão da subordinação do trabalho ao capital. 1991. 107 f. Dissertação (Mestrado em Ciências Sociais) - UFBA, Salvador, 1991.

CUNHA, Euclides da. Os sertões. São Paulo: Nova Cultural, [1901] 2002. $370 \mathrm{p}$.

DANTAS, Mônica Duarte. O feudo: A casa da torre de Garcia d' Ávila: Da conquista dos sertões à independência. Hispanic American Historical Review. Durham, EUA, v.82, n.4, p.799-801, 2002. 
DRUMMOND, José Augusto Leitão. A legislação ambiental brasileira de 1934 a 1988: comentários de um cientista ambiental simpático ao conservacionismo. Ambiente $\mathcal{E}$ Sociedade, Campinas,SP, v.2, n.3/4, p.127-149, 1998-1999.

FAORO, Raymundo. Os donos do poder: formação do patronato político brasileiro. 11.ed. São Paulo: Globo, 1997. $750 \mathrm{p}$.

FERNANDES, B. M. Questão agrária, pesquisa e MST. São Paulo: Cortez; Autores Associados, 2001. 120 p. (Coleção polemicas do nosso tempo, 92).

FREITAS, A. F. G. de; ROCHA, A. L. B. de C.; MELLO, M. A. G. M. Diagnóstico parâmetro para avaliação do PDRINordeste da Bahia, $1^{a}$. Etapa. O Sertão da Bahia - aproximações para análise de sua formação histórica. Salvador: SEPLANTEC-SEAGRI-CAR, 1984. v. 2

FREYRE, Gilberto. Casa-Grande \& Senzala: formação da família brasileira sob o regime da economia patriarcal. 29.ed. Rio de Janeiro: Record, 1994. 406 p.

. Nordeste: aspectos da influência da cana sobre a vida e a paisagem do nordeste do Brasil. 3.ed. Rio de Janeiro: Livraria José Olympio, [1937]1961. 183 p.

GALEANO, Eduardo. As veias abertas da América Latina. 36.ed. Rio de Janeiro: Paz e Terra, [1976]1994. 307 p. (Coleção estudos latino americanos, v.12 - aumentada de um pósfacio).

GALIZONI, Flávia Maria. A terra construída. 2000. 92 f. Dissertação (Mestrado em Antropologia Social) - FFLCH, USP, São Paulo, 2000.

GARCEZ, Angelina N. R. Fundo de Pasto: um projeto de vida sertanejo. Salvador: INTERBA/SEPLANTEC/CAR, 1987. $109 \mathrm{p}$.

. Leis de terra do Estado da Bahia. Salvador: Seagri/ CDA, 2001. 571 p.

HOLANDA, S. B. de. Raízes do Brasil. 12.ed. Rio de Janeiro: J. Olympio, [1936]1978. 158 p.

INTERBA-SEAGRI. Projeto Fundo de Pasto - Oliveira dos Brejinhos. 1985. Disponível no Centro de Documentação da CAR.

MEYER, Doris Rinaldi. A terra do santo e o mundo dos engenhos: estudo de uma comunidade rural nordestina. Rio de Janeiro: Paz e Terra, 1979. 125 p. (Série estudos sobre o Nordeste,9).

NEVES, Erivaldo Fagundes. Estrutura fundiária e dinâmica mercantil: Alto Sertão da Bahia, séculos XVIII e XIX. Salvador: EDUFBA/UEFS, 2005. 200 p.

Uma comunidade sertaneja: da sesmaria ao minifúndio (um estudo de história regional e local). Feira de Santana,BA: EDUFBA, 1998. 358 p.

OLIVEIRA, D. L.; ROTHMAN, F. D. Desterritorialização de populações locais sob a ótica da justiça ambiental: abordagem dos conflitos do projeto de integração do rio São Francisco. In: SEMINÁRIO NACIONAL MOVIMENTOS SOCIAIS, 2, 2007, Florianópolis, Anais... Florianópolis: UFSC, 2007.

OLIVEIRA, Ariovaldo Umbelino. Disponível em: http:// www.radioagencianp.com.br. Acesso em: 15 maio 2008.

PÁDUA, José Augusto. Um sopro de destruição: pensamento político e crítica ambiental no Brasil escravista, 1786-1888. Rio de Janeiro: Jorge Zahar Editores, 2002. $318 \mathrm{p}$.

PDRI-Nordeste. Fundos de Pasto: aspectos jurídicos e sócio-econômicos. Salvador: 1982.

POLANYI, Karl. A grande transformação: as origens da nossa época. 2.ed. 9. reimpressão. Rio de Janeiro: Elsevier, [1944] 2000. 349 p.
PRADO JR., Caio. História e desenvolvimento: a contribuição da historiografia para a teoria e prática do desenvolvimento brasileiro. 3. ed. São Paulo: Brasiliense, [1968] 1989. 142 p. (Tese de livre docência, 1968).

RAMOS, Alberto Guerreiro. A redução sociológica: introdução no estudo da razão sociológica. Rio de Janeiro: Ed. Tempo Brasileiro, 1965. 268 p. (Coleção tempo novo,2).

RAZAC, Olivier. Histoire politique du barbelé. Paris: La fabrique, 2000. $111 \mathrm{p}$.

RIBEIRO, Darcy. O povo brasileiro: a formação e o sentido do Brasil. São Paulo: Companhia das Letras, 1995. 476 p. SABOURIN, Eric; MARINOZZI, Gabrio. Recomposição da agricultura familiar e coordenação dos produtores para a gestão de bens comuns no Nordeste brasileiro. Política \& Trabalho. João Pessoa, n.17, p.80-90, set. 2001.

SEPLANTEC/CAR. Fundos de Pasto: uma prática de trabalho comunitário na pequena produção - um estudo de caso no município de Uauá. Salvador: CAR, 1983. (Disponível na Biblioteca da CAR).

SILVA, José Graziano da. O que é questão agrária. São Paulo: Brasiliense, 1980. 112 p.

SZMRECSÁNYI, Tamás. Pequena história da agricultura no Brasil. São Paulo: Ed.Contexto, 1990.

WANDERLEY, Maria de Nazareth Baudel. Capital e propriedade fundiária: suas articulações na economia de Pernambuco. Rio de Janeiro: Paz e Terra, 1979a. 145 p. (Série estudos sobre o Nordeste,3).

Capital e propriedade fundiária na agricultura brasileira. In: BRAZ, J. de A. Reflexões sobre a agricultura brasileira. Rio de Janeiro: Paz e Terra, 1979b. p.15-40. 


\section{FROM SESMARIAS TO RESISTANCE TO ENCLOSURE: historical reasons for back of pasture}

\section{Luiz Antonio Ferraro Jr Marcel Bursztyn}

This paper reviews the historical reasons for the emergence of the category of back of pasture. We made use of secondary data collected from government reports and obtained in interviews with technicians, pastoral communities and agents. The backs of pasture were just grazing areas not surrounded by Caatinga, used for communal grazing. This pattern of occupation that has developed throughout the Northeast semi-arid region was gradually usurped in a process similar to the British enclosures. In Bahia, with the advances of capital over these areas from the 1970s, there were regional articulations and institutional support that stimulated various resistances. "Back of pasture" came to denote not only the areas, but social groups that depended on them and therefore advocated them. The formerly only regional term Back of Pasture, became widespread throughout the state, especially after its quoting in the constitution of Bahia. Family ties in these communities also contributed to the resistance of this form of occupation.

KEYWORDS: backs of pasture enclosures, land grabbing, communal lands, caatinga.

\section{DES SESMARIAS À LA RÉSISTANCE AUX CLÔTURES: les raisons historiques des fonds de pâturage}

\author{
Luiz Antonio Ferraro Júnior \\ Marcel Bursztyn
}

L'article récupère les raisons historiques du surgissement d'une catégorie appelée fonds de pâturages. Des données secondaires ont été relevées dans les rapports gouvernementaux et obtenues par des interviews faites avec des techniciens, des agents de la pastorale et les communautés d'éleveurs. Les fonds de pâturage étaient tout simplement des terres, dans la Caatinga (savane), qui n'étaient pas clôturées et qui étaient utilisées comme pâturage communal. Ce type d'occupation qui s'est développé dans toute la région semi-aride du nord-est a été peu à peu usurpé par un processus similaire à celui des enclos anglais. A Bahia, avec les avancées du capital sur ces terres, depuis les années 1970, il y a eu des ententes régionales et des appuis institutionnels qui ont stimulé divers types de résistances. "Fonds de Pâturage" a commencé à désigner non seulement ces terres mais aussi les groupes sociaux qui en dépendaient et les défendaient. L'expression "Fonds de Pâturage", qui avant n'était que régionale, s'est répandue dans tout l'état, surtout après avoir été insérée dans la constitution de Bahia. Les liens familiaux de ces communautés ont aussi contribué à créer une résistance face à ce type d'occupation.

Mots-Clés: Fonds de Pâturages, enclos, clôture, accaparement de terres, terres communales, caatinga.

Luiz Antonio Ferraro Júnior - Doutor em Desenvolvimento Sustentável pela Universidade de Brasília. Professor adjunto da Universidade Estadual de Feira de Santana. Sua publicação importante mais recente é Managing the remaining commons: challenges to sustainability in the Brazilian Northeast. Working papers (Harvard University. Center for International Development. Online), v. 28, p.1-23, 2008; Environmental education and degraded areas restoration: public policies commited to diversity. In: Ricardo Ribeiro Rodrigues; Sebastião Venâncio Martins; Sérgius Gandolfi. (Org.). High diversity forest restoration in degraded areas: methods and projects in Brazil. New York: Nova Science Publishers Inc., 2007, escrita em parceria com SORRENTINO, M.; SILVA, M. M. R.

Marcel Bursztyn - Doutor em Desenvolvimento Econômico e Social e em Economia. Pós-doutor em Políticas Públicas. Professor associado da Universidade de Brasília, junto ao Departamento de Sociologia e ao Centro de Desenvolvimento Sustentável. Senior Research Fellow na Kennedy School of Government - Sustainability Science Program, Harvard University (2007-2008), com bolsas Harvard, Fulbright e Capes. Última publicação: Fonseca, I.F. e Bursztyn, M. 2009. A banalização da sustentabilidade: reflexões sobre governança ambiental em escala local. In: Revista Sociedade e Estado 24(1):17-46. http:// www.scielo.br/pdf/se/v24n1/a03v24n1.pdf 